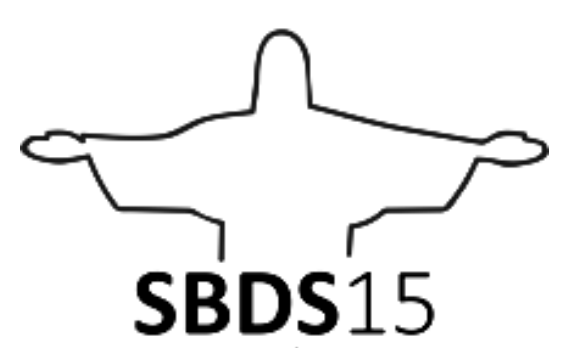

5 SIMPÓSIO DE DESIGN SUSTENTÁVEL

Rio de Janeiro, 11 de novembro a 13 de novembro de 2015

\title{
AS REDES SOCIAIS E A MOBILIZAÇÃO: espaço para o design
}

\author{
Isabel Cristina d'Avila Oliveira \\ Unisinos \\ i.davila@terra.com.br
}

\begin{abstract}
Resumo: Há mais de duas décadas, o design preocupa-se em refletir sobre o desenvolvimento de processos que levem à inovação e a melhorias socioambientais. Autores como Ézio Manzini, Anna Meroni e François Jégou, entre outros, propõem projetos voltados a repensar a maneira como é organizado o cotidiano das comunidades. Esses autores representam alguns dos designerspesquisadores que desenvolvem projetos de inovação socioambiental na busca de alternativas para um futuro mais sustentável. Manzini e Jégou (2003) afirmam que a falência do modelo de bem estar, que associou a melhor qualidade de vida ao consumo de bens e serviços amplamente disponibilizados pela industrialização, levou à necessidade de pensar um novo posicionamento do designer. Neste sentido, os designers usam da capacidade de trabalhar a prática projetual para além de desenvolver produtos e serviços e começam a aperfeiçoar processos capazes de suportar a constituição de rede de atores, que influem nos direcionamentos sobre a dinâmica das cidades. Este artigo se propõe a refletir sobre os atores sociais, as redes sociais e a participação do designer na ocupação de um novo espaço, que está sendo construído pela participação dos atores sociais.
\end{abstract}

Palavras-chave: design, redes sociais, ator social, mobilização

\begin{abstract}
For more than two decades, design wories to reflect about de development of processes that lead to innovation and social-enviroment improvements. Authors Ézio Manzini, Anna Mewroni and Françoise Jégou, among others, propose projects direct to rethink the way to organize communitieseveryday. These authors represent some of the designers-researchers to develop projects of innovation social-enviroment on the quest for alternatives to a more sustainable future. Manzini and Jógou (2003) state that the bankruptcy of this model of well-being, as a consequence of a consumption increasement for the facilities provided to the industries for a better life lead the necessity to think a
\end{abstract}


new step for the designer. On this way, designers get the projectual ability to work on beyond develpoping products and services and start to improve processes to support the network of actors that have influence on managing and directing cities. This article has the intention to reflect about the social actors, networks and the participation of designers occupying a new space that is being built by social actors.

Keywords: social networks, social actor, mobilization, design

\section{INTRODUÇÃO}

Em encontro com o governador do RS, Tarso Genro, no ano de 2013, Manuel Castells refere-se ao Gabinete Digital ${ }^{1}$ como uma oportunidade de construção participativa e aberta para toda a população, de forma a ter acesso às diversas agendas do estado. Segundo Castells, "...a participação digital é fundamental para a conexão entre a sociedade e as instituições. Sem participação a democracia se desgasta. A participação no nosso tempo é digital, ou não é." (CASTELLS, 2013c site do governo do estado do RS). Nesta fala, o autor destaca dois pontos principais de suas pesquisas: a democracia, tema que sempre foi central; e a participação do sujeito através das redes digitais. Assim como atribui à liberdade (um dos frutos possíveis da democracia) o mais importante direito do ser humano, por entender que apenas pelo seu exercício teremos autonomia para outras práticas (CASTELLS, 1999), também confere à participação social a condição básica aos sujeitos agentes de mudança. Chama a atenção, porém, sobre a necessidade de entender a inclusão social como um processo cada vez mais entrelaçado à inclusão digital e seus desdobramentos via tecnologias e formação em redes. Para o autor, o conceito de redes alinhado às mudanças tecnológicas dos últimos vinte anos "passou a caracterizar quase todas as práticas sociais, incluindo a sociabilidade, a mobilização sócio-política, baseando-se na Internet em plataformas móveis." (CASTELLS, 2013b).

As redes sociais são, antes de tudo, redes que se formam no amálgama social. Touraine entende a sociedade como:

"um sistema de meios, de técnicas, de regras, de formas de organização, mas creio que a finalidade é nossa definição...nossa finalidade é de garantir que haja uma criação da sociedade pelos seres humanos, pelos indivíduos, e não como simples consumidores" (TOURAINE 1993).

Para Castells, a sociedade de redes é uma sociedade em que as atividades principais nas quais as pessoas estão engajadas são organizadas horizontalmente. Porém, o autor alerta sobre o que seja agir em rede; uma coisa é estar constantemente interagindo com pessoas na velocidade da luz, outra é, simplesmente, ter uma rede de amigos e pessoas (CASTELLS, 2012).

Em artigo no qual discorre sobre o movimento de julho de 2013, no Brasil, Frei Betto $(2013$, ) reafirma o poder de mobilização das redes e tece uma reflexão sobre a nova forma de organização potencializada no ambiente digital "o poder convocatório das redes sociais é inegável. Elas possuem uma capilaridade que supera qualquer outro meio de comunicação. $\mathrm{E}$ carecem de censura ou editoração falaciosa" (BETTO, 2013). Porém, o fato de estar exposto a um poderoso volume de conhecimentos não é garantia de seu uso adequado, a ponto de gerar impacto nas ações sociais empreendidas. Para Castells (1999), as sociedades sempre foram

\footnotetext{
${ }^{1}$ O gabinete Digital foi criado em 2011 com o objetivo de ouvir a opinião dos cidadãos em assuntos como saúde, planejamento urbano e educação. O governo lança um questionamento à sociedade sobre temas de grande importância para o Estado e a população tem um prazo para enviar contribuições através do site. As propostas recebidas são sistematizadas e disponibilizadas para a votação no portal. No final do processo, os autores das contribuições priorizadas na votação participam de um encontro presencial com o Governador debatendo os encaminhamentos das propostas levantadas. (Relatório do Gabinete Digital, 2012)
} 
alicerçadas na informação e no conhecimento e o que as diferencia da constituição atual é o volume a que as pessoas estão expostas e a rapidez de acesso e compartilhamento. Para além de acessar informações, é fundamental deter a capacidade intelectual de utilizar adequadamente os dados, de maneira a que estes apresentem consistência e subsidiem as tomadas de decisão.

Portanto, na medida em que as redes sociais potencializam-se na definição das prioridades, e demandam inovações determinadas pelo interesse comum de múltiplos atores, a questão da criação compartilhada cresce. Na horizontalidade das redes, os atores participam ativamente. Do ponto de vista do design, isso significa dizer que nas redes projetuais, o designer irá dividir o espaço de projeto com não-designers. Daí a necessidade de posicioná-lo agora como facilitador, e não criador único. Os novos processos, surgidos a partir dos modelos de rede virtual, são percebidos no design em estruturas projetuais de co-design (SANDERS, 2008).

O objetivo deste artigo é tratar da aproximação do design com os movimentos sociais constituídos no ambiente das redes sociais. Para tanto, trazemos a experiência do Gabinete Digital do RS na consulta pública em relação à melhoria da saúde pública do estado. Referencia-se mais especialmente nos estudos de Castells e Touraine para tratar da mobilização social e das redes sócias e nas pesquisas de Manzini para tratar do design na proposição por processos de sustentabilidade.

\section{O DESIGN E A QUESTÃO SOCIAL: desenvolvimento}

A participação da sociedade civil propondo temas e novas formas de organização sócio-ambiental cresce nos últimos anos. Esse fluxo de trocas sociais pode ser observado nas matérias veiculadas na mídia formal e nos movimentos que se avolumam tendo por meio a plataforma da internet. Paul Hawken, ambientalista norte-americano (HAWKEN, apud THACKARA, 2008 - DOTT) calcula que há mais de um milhão de projetos de sustentabilidade ambiental sendo desenvolvidos no mundo por instituições formadas por cidadãos. Porém, o desconhecimento de uma metodologia necessária à organização de suas propostas reduz a efetividade do trabalho de muitas delas (Dupas, 2008). Vários centros de estudo em design têm examinado as competências necessárias ao designer que pretende projetar para a melhoria das questões sociais (MARGOLIN; MARGOLIN, 2004; KIRKBRIDE, 2008). Há em comum entre eles o entendimento da necessidade da aproximação com o conhecimento teórico e prático dos especialistas em condução de questões de empoderamento social. Estão nesse grupo os assistentes sociais e os líderes de instituições não governamentais.

Não são recentes os questionamentos sobre a importância do uso dos métodos de design para possibilitar melhorias nos processos de desenvolvimento sócio-ambientais. Papanek já conduzia estudos desta natureza nos anos 1970 (PAPANEK, 1985). Mas, notadamente, um dos maiores impulsos na área iniciou há duas décadas, com os trabalhos de Ézio Manzini, ligados às pesquisas europeias. A preocupação central do autor é inserir o design no debate sobre mudanças na cultura de consumo, pensando maneiras de dispor suas em favor de modelos sustentáveis da vida em comunidade. Segundo Manzini:

"Se o papel ampliado do projeto é fazer o mundo mais habitável, uma maneira de fazêlo é, na minha opinião, a de propor um novo critério de qualidade, o que existe no jardim, e no cuidado que ele exige, como um metáfora de referência". (MANZINI, 1992, p. 1, tradução da autora).

Manzini (2008) observa que as questões de sustentabilidade atravessam um momento que pede transformações fundamentais e sistêmicas. É preciso propor soluções que partam do cotidiano e da prática local e caminhem em direção à evolução de um modelo que permita replicar conceitos e difundir melhorias (MANZINI, 2006). Desta forma, a contribuição do design está em projetar processos capazes de suportar a construção de inovações concebidas a partir das experiências locais. É o conjunto de conhecimentos que pode 
organizar a prática das ações sociais, por outro, estamos tratando da própria realização de tais ações (MANZINI, 2006).

Para Manzini $(2007,2008)$ os designers podem desempenhar o papel de agentes da sustentabilidade desde que sejam capazes de entender a conjuntura na qual estão inseridos. Chama atenção à necessidade de assumirem uma postura distinta da adotada até então frente às demandas por projetos de produtos e serviços, devendo considerar o impacto ambiental e social advindos do excessivo lançamento de artefatos. A chave, segundo o autor, está na proposição de projetos mais focados no desenvolvimento de processos, do que produtos. (MANZINI, 2007).

\section{A APROXIMAÇÃO DO DESIGN COM OS MOVIMENTOS SOCIAIS}

A mobilização social2 por si só, não se traduz em inovações positivas. Depende da vontade dos atores em permanecer agindo; da capacidade de articulação para interferir nas instituições, ou no panorama de suas próprias vidas; e na condição de manterem o interesse do grupo adepto ao movimento.

Ao colocar em lados distintos a atitude de consumidor e de propositor, Touraine se aproxima de Manzini, pois que ao fazer a distinção entre o consumo indiscriminado de um inconsciente, e o consumo qualificado do consumidor crítico, Manzini assenta o consumidor engajado como ator, talvez ativista, de uma nova forma de sociedade, em oposição ao inconsciente, que apesar de poder se fazer ouvir, permanece absorvendo o que lhe é oferecido (2012). Quando, há mais de duas décadas, Manzini voltou suas pesquisas à inovação social, seu foco estava em colocar as competências projetuais do design a favor da construção de projetos inovadores e socialmente responsáveis (2007).

Em Manzini, o espaço para atuação do designer num ambiente de rede, e considerando as demandas sociais por participação e efetividade, está num futuro que se apresenta "small, local, open and connected" (2010). Para o autor, o primeiro desafio das novas conformações de redes é a aprendizagem social de como lidar com a tecnologia e de como os designers podem transpor sua forma de projetar de maneira ampla, aberta e colaborativa.

“Estes exemplos significativos de sustentabilidade são o resultado de uma miríade de iniciativas postas em movimento por cidadãos locais, associações, empresas e governos locais que, a partir de diferentes pontos de partida, estão se movendo em direção a ideias similares de bem estar e de produção: especificamente, um senso de comunidade com base em compartilhar bens comuns, e um sistema de produção criado por redes de parceiros de colaboração, tanto locais como globais. E, apesar de sua diversidade, eles compartilham uma característica fundamental comum, todos eles se referem a lugares, ou seja, os recursos locais e as comunidades locais." (MANZINI, 2011, p. 101 e 102, tradução da autora)

Na sociedade em rede digital, as atividades de interesse da população são organizadas em estruturas horizontais não nucleares e as relações verticais dão lugar ao co-design e a substituição da autoria do sujeito para um possível anonimato de ideias. Nessa caminhada, que inicia pelo profissional criativo, conhecido por suas peças assinadas, e chega até o profissional que empurra a inovação dividindo o espaço do projeto com outros atores, os designers se esforçam para desenhar seu novo perfil profissional. Para o Patrocínio (2013) no co-design o projeto é compartilhado entre os usuários e a função do designer é posicionar-se como catalisador das ideias.

\section{1 a participação social em rede}

\footnotetext{
2 Mobilizar é convocar vontades para atuar na busca de um propósito comum, sob uma interpretação e um sentido também compartilhados. (TORO, 2004)
} 
O Estado democrático pressupõe a disposição em considerar a participação dos cidadãos na tomada de decisões. Os governos da primeira metade do século XX são influenciados pela teoria de Schumpeter (1961) na maneira pela qual entendem a conformação do Estado democrático. Para esse autor, o cidadão não tem interesse nem capacidade de exercer a titularidade na tomada de decisões; identifica o processo eleitoral como a instância máxima da participação política. Assim, na sua concepção, os cidadãos participam da construção do Estado apenas através do ato de deliberarem em quem confiarão para a condução do processo.

As respostas para a melhoria das condições de vida em sociedade surgem a partir da capacidade de muitas pessoas em agir no seu cotidiano, criando na imaginação um futuro desejável, que ainda não está planejado, e indo à busca de uma maneira de se fazer materializar. $O$ ator social está no centro dessa mudança. Para Touraine, o sujeito que promove os movimentos sociais é um resistente e na medida em que toma para si a titularidade das mudanças ele torna-se um ator, ou seja, aquele que atua, que age. (2011). Neste conceito, na condição de atores engajados, somos soberanos para definir quais rumos almejamos à nossa vida.

Na prática do design, projetar em rede para inovação social significa considerar a satisfação de necessidades humanas específicas, com a iniciativa colaborativa de diversos atores envolvidos, usando a criatividade e as ferramentas projetuais para gerar transformações disruptivas. Para Manzini (2008), os designers precisam dar passos em direção de entender o contexto em que atuam, e se reorientar em direção à sustentabilidade, sempre considerando os aspectos socioambientais. Uma das características relevantes do design, no desenvolvimento das propostas de âmbito socioambiental conduzidas pela sociedade civil, está em suportar o desenvolvimento de produtos e serviços alinhados às expectativas das instituições e dos demais atores que atuam junto a ela. A relevância da ação do designer está diretamente relacionada à pertinência do tema tratado e ao estágio de amadurecimento da discussão. Ou seja, quanto mais imaturo o grupo, menor a condição de debate e articulação das ideias, nesse panorama, as propostas do designer tendem a se perder em debates inócuos. Por temas pertinentes, temos todos os debates alinhados com as questões da atualidade e de interesse de grupos com poder de influência.

É nesse viés de pertinência e atualidade que estão concentrados os temas tratados pelo Gabinete Digital do RS.

\section{2 o gabinete digital e a participação em rede}

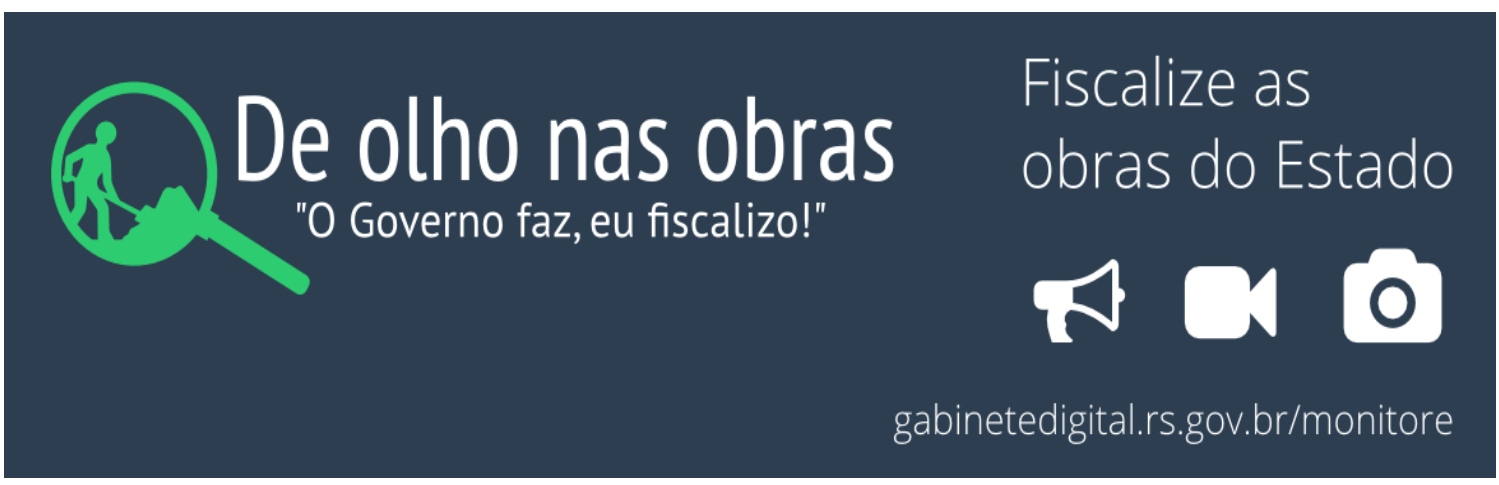

Figura 1 -“Banner do site do Gabinete Digital do RS"

Fonte: site gabinete digital

O Gabinete Digital foi um portal para participação popular dos cidadãos gaúchos, desenvolvido na administração do Governador Tarso Genro, em 2011 e permaneceu ativo até o final da administração, em final de 2014. Objetivava possibilitar a participação virtual da 
população em geral, através de um instrumento disponibilizado na rede online, para aproximar cidadãos e governo. Para além de receber reclamações, sugestões e elogios (grades de praxe nesses contatos), o Gabinete Digital está aberto para proposição de agendas pelos cidadãos, consultas públicas, fiscalização pública de obras e gastos, recebimento de propostas populares e votação dos cidadãos nas propostas do governo. (site Gabinete Digital). Uma das vantagens do Gabinete é possibilitar igualdade de acesso à participação dos moradores de regiões próximas à capital e do interior.

Em pouco mais de um ano de sua criação, o Gabinete Digital recebeu quatro prêmios nacionais e um prêmio internacional:

- Prêmio Bank Beneficiary Feedback Awards, concedido pelo Instituto do Banco Mundial

- Prêmio CONIP de Excelência em Inovação na Gestão Pública Prof. Francisco Romeu Landi, concedido pelo Instituto de Estudos de Tecnologias para Inovação na Gestão Pública (ITIP)

- Prêmio E-gov, de excelência em governo eletrônico, concedido pela Associação Brasileira de Entidades Estaduais de Tecnologia da Informação e Comunicação (ABEP)

- Prêmio A Rede 2011, na categoria Inovação na Gestão Pública, promovido pela Revista A Rede

- Prêmio TI \& Governo 2011, na categoria e-democracia, concedido pela Plano Editorial" (site Gabinete Digital)

Em 2011 a primeira iniciativa da ferramenta "Governador Pergunta", do portal, buscava respostas à pergunta: "Como podemos melhorar o atendimento na saúde pública?". Durante o mês de novembro, foram encaminhadas mais de 1.300 propostas, publicadas no portal para consulta e, ao final do mês, abertas à votação online. Os autores das cinquenta mais votadas foram recebidos pelo governador para discutir as iniciativas do governo em resposta às demandas da população. A 16a. desta lista tratava das questões de qualidade e agilidade do diagnóstico e acesso ao tratamento das mulheres com câncer de mama. Essa proposta havia sido encaminhada pela vice-presidente do Instituto da Mama do RS e conselheira do Conselho Municipal de Saúde.

A participação bem sucedida da ativista, representando as mulheres gaúchas com câncer de mama, resultou de uma ação que nasceu nas bases da articulação do Instituto da Mama. A proposta que fora encaminhada representava as questões que norteiam o trabalho do instituto. Desta forma, a votação expressiva foi consequência da mobilização junto às voluntárias, aos conselheiros do conselho municipal de saúde, simpatizantes e trabalhadores da área da saúde, principalmente. Parte dessa mobilização resultou de um trabalho corpo a corpo, parte virtualmente, via site, e-mail, facebook. A rede digital foi fortalecida também pela rede de contatos diretos.

\section{3 o encerramento das atividades}

O projeto do gabinete digital gaúcho foi uma demonstração do esforço das instituições formalmente constituídas em se incluírem no movimento das redes sociais da internet. Especificamente, o Gabinete Digital foi constituído para abrir o espaço de discussão da população, ouvir a opinião dos cidadãos sobre as questões pertinentes ao Estado e criar condições de fiscalização à distância através de um meio digital. Toma-se a liberdade para também entendê-lo como sendo uma forma do governo analisar as contribuições da população para medir sua aceitação, agendas de interesse para eleições e possíveis movimentos para os quais entenda necessário se antecipar.

Podemos chamar este projeto de um trabalho de co-design? Inicialmente, mesmo que nos permitamos a liberdade de inferir a participação de designers na concepção do projeto do gabinete e que este seja o resultado da criação entre atores do governo, da sociedade civil e representantes de grupos de interesse, não podemos afirmar que seja "a mudança de poder do design para o cliente, por meio do designer, para o usuário final. Um caminho para o setor público para garantir que seus serviços de entregar o que o público quer e precisa." (DESIGN 
COUNCIL, 2013). Isto porque, o cidadão assistido pelo Gabinete ainda não ocupa a posição de comandar as mudanças do governo. Ao opinar, ele influi, mas não determina.

Por outro lado, essa iniciativa já constituída apresentou as bases para o desenvolvimento do projeto de design, que poderá potencializar os resultados do Gabinete. Meroni (2008), entende que o design é um processo colaborativo que permite a troca de experiências e saberes entre diversas atividades profissionais envolvidas no projeto, ampliando sua capacidade de solucionar problemas. É um sistema de regras, crenças e valores organizados para lidar com o ambiente interno e externo das organizações. O governo pode se beneficiar dessas características na tentativa de impulsionar mudanças nos setores de seu interesse num sistema de representação de igual peso com a sociedade civil.

Com a mudança de governo, a partir de janeiro de 2015, a plataforma é objeto de reavaliação da nova equipe da Secretaria de Comunicação do Rio Grande do Sul. Partindo do conceito de que o cidadão deve entender o governo como um todo, sem que haja necessidade de fragmentar os acessos por temas, ou órgãos, algumas questões mostram-se muito importantes: otimizar os contatos da população com o Estado, concentrando toda a comunicação no site do governo, interagir com facebook e demais ferramentas online. As propostas do modelo anterior do Gabinete, enviadas pelos cidadãos, também estão passando pela reavaliação do modelo. A tendência é que a maioria das serviços continue e incorpore o canal no site do governo atualizado.

\section{CONCLUSÃO}

Como Castells afirma (1999), comunicar é um processo que carrega consigo a vontade de uns deterem poder pelos outros. Assim na rede, por mais democrática, coletiva e fluída que seja, há um potencial impulso de dominação das ideias de uns sobre a de outros. Quanto mais as instituições se aproximarem dos projetos operados em rede e quanto mais essa tecnologia evoluir a ponto de introjetar aspectos do co-design, mais se caminhará para uma nova forma de entender essa conexão entre os atores de diversas procedências. É fundamental que os designers creiam na possibilidade dos projetos gerarem mudanças positivas para que se sintam convidados a trabalhar no desenvolvimento de novos arranjos sociais. Participar da rede com este intuito não é só um processo de uso da tecnologia, muito além disso, é a ocupação de um espaço de empoderamento. O designer participa da rede social em projetos de inovação e se orienta no sentido de abrir espaço para a defesa de pensamentos e técnicas que devem impactar em mudanças no modo de ser da estrutura social.

Ao tratarmos de criação coletiva, precisamos considerar que os atores são pessoas, grupos e também instituições e que ao passo que cada um desses se inclui na rede, mais difícil se torna manter as relações não hierarquizadas. A dificuldade em conciliar esses interesses e atores distintos enfraquece a rede? Em nossa opinião, não. Desde que entendamos a necessidade de usar as informações que obtemos para transformá-las em ação consciente e produtiva.

\section{REFERÊNCIAS}

BETTO, Frei. Disponível na internet em http: <http://www.freibetto.org/index.php/artigos/48redes-sociais-proveitos-e-riscos-frei-betto>. Acesso em 05/01/2014.

CASTELLS, Manuel. A sociedade em rede. São Paulo: Paz e Terra, 1999.

CASTELLS, Manuel, A Rede Torna Mais Difícil a Opressão. Entrevista cedida à Zero Hora, 2013b.

CASTELLS, Manuel. Não basta um manifesto nas redes sociais para mobilizar as pessoas. Entrevista Cedida à Folha de São Paulo, 2013c.

CASTELLS, Manuel. Redes de Indiganção e de Esperança. Rio de Janeiro, Zahar, 2013d. 
CROSS, N. Designerly Ways of Knowing: Design Discipline Versus Design Science. In: Design Issues. V. 17, No. 3, Cambridge: MIT Press Journals. 2001. pp. 49-55

DESIGN COUNCIL. Disponível na internet por http em: http://www.designcouncil.org.uk/resources-and-events/designers/design-glossary/co-design/. Acesso em 20/10/2013.

DUPAS, G. Atores e Poderes na Nova Ordem Global. São Paulo, Ed. Unesp, 2005.

EMUDE, Relatório 2011. Disponível na internet por http em : <http://www.sustainableeveryday-project.net/emude/>. Acesso em 15/10/2013

GABINETE DIGITAL RS. Disponível na internet por http em: <http://gabinetedigital.rs.gov.br/> . Acesso em 15/01/2014.

GOVERNO DO ESTADO DO RS. Disponível na internet por http em: <http://www.rs.gov.br/conteudo/15420/governador-recebe-o-sociologo-espanhol-manuelcastells->. Acesso em 05/01/2014.

IMAMA. Disponível na internet por http em: <http://www.imama.org.br/index.php>. Acesso em 11/12/2011.

KIRKIBRIDE, Robert. Proposals for A Good Life: Senior Thesis Projects from Parsons Product Design 2003-08. In Changing The Change. Design visions proposals and tools, 2008.

MANZINI, Ezio. The garden of objects: designing for a world to take care of, 1992.

MANZINI, Ezio. Ideas of wellbeing. beyond the rebound effect, paper presented to the Sustainable Services \& Systems: Transition towards Sustainability, Amsterdam, October 2001 (paper to be published)

MANZINI, Ezio. Scenarios of sustainable wellbeing. Design philosophy papers, n.1,v.1,2003. Disponivel na internet por http em: <http://www.desphilosophy.com/dpp/dpp_index.html>., Acesso em 03/05/2013

MANZINI, Ezio. The scenario of the multi-local society, in Chapman J. and Gant N., Designers, Visionaries plus other stories. London: Earthscan, 2007.

MANZINI, Ezio. Design para a inovação social e sustentabilidade: comunidades criativas, organizações colaborativas e novas redes projetuais Rio de Janeiro: E-papers, 2008. (Cadernos di Grupo de Altos Estudos; v01) 104

MANZINI, Ezio.; JÉGOU, François. Collaborative services: social innovations and design for sustentainability. Edizioni Poli.Design, 2008.

MANZINI, Ezio. Small, Local, Open and Connected: Design Research Topics in the Age of Networks and Sustainability," in Journal of Design Strategies, Volume 4, No. 1. , 2010.

MANZINI, Ezio. The New Way of the Future: Small, Local, Open and Connected. (2011). Social Space. , 100-105. Social Space.

MANZINI, Ezio. Scenarios of sustainable wellbeing. Design philosophy papers, n. 1, v. 1, 2003. Disponivel na internet por http em: <http://www.desphilosophy.com/dpp/dpp_index.html>. Acesso em 15/01/2014.

MANZINI, E., LEONG B. D. Strategic Design and design for Sustainability. A general overview and some consideration ion the Chinese context, paper presented to the Tsinghua 2001 China.

MARGOLIN, Victor.; MARGOLIN, Sylvia. Um Modelo Social de Design: questões de prática e pesquisa. Revista Design em Foco, vol. I, núm. 1, julho-dezembro, 2004, pp. 43-48, 
MERONI, Anna. Strategic design: where are we now? Reflection around that foundations of a recent discipline. Strategic Design Research Journal, 1 (1): 31-38 julho-dezembro 2008.

PAPANEK, Victor. Design for the real world. s.I.: Thames and Hudson, 1985

SANDERS, E.B.N.; STAPPERS, P.J. Co-Creation and the New Landscapes of Design. Codesign: International Journal of Cocreation in Design and the Arts, 10:2, 5-18, 2008.

SCHUMPETER, Joseph A. Capitalismo, Socialismo e democracia. Rio de Janeiro: Editora Fundo de Cultura, 1961

THACKARA, John, Design of the Times (Dott 07). Disponivel na internet por http em: <http://www.thackara.com>. Acesso em 10/01/2014.

TORO, Jose Bernardo; WERNECK, Nisia M.D.F. Mobilização social: um modo de construir a democracia e a participação. UNICEF, Brasil, 1996. Disponível em: <http://www.aracati.org.br/portal/pdfs/13_Biblioteca/Publicacoes/mobilizacao_social.pdf $>$. Acesso em 19/01/2013.

TOURAINE, Alain. Depois da Crise. Parte 1. As Crises em Curso. Instituto Piaget. 2011.

TOURAINE, Alain. Entrevista à RTBF Liége, 1993, Disponível na internet por http em: http://www.youtube.com/watch?v=BAWd9hLJYOw> 